\title{
Chapter 6 \\ Valuing in Mathematics Learning Amongst Ghanaian Students: What Does It Look Like Across Grade Levels?
}

\author{
Ernest Kofi Davis, Monica E. Carr and Ernest Ampadu
}

\begin{abstract}
In this chapter, the authors explored the effects of grade levels on what students find important in their mathematics learning in Ghana. A survey involving 1,256 primary, junior high and senior high school students was conducted in the Cape Coast Metropolis of Ghana, using the WIFI questionnaire. It revealed that the Ghanaian students valued attributes such as achievement, relevance, fluency, authority, the use of ICT, versatility and Strategies in their learning of mathematics. The oneway Multivariate Analysis of Variance (MANOVA) was used to investigate whether significant differences exist in what students valued in mathematics across grade levels. The results revealed a significant effect of grade level on students' valuing in mathematics. Implications for research and curriculum delivery are provided.
\end{abstract}

Keywords Values $\cdot$ Mathematics $\cdot$ Learning $\cdot$ Grade levels $\cdot$ Ghana

\subsection{Introduction}

The past fifteen years have seen growing interest and research activities around the world into the role of values in mathematics education. Initial research conducted through the lens of values and valuing involved small scale studies of teacher valuing in mathematics education (Chin and Lin 2000). The inception of the Third Wave Project in 2008 facilitated the large scale study of valuing in mathematics on what students value in their mathematics learning (Seah and Wong 2012). This created

\footnotetext{
E. K. Davis $(\varangle)$

School of Educational Development and Outreach, College of Education Studies, University of Cape Coast, Cape Coast, Ghana

e-mail: ekdavis@ucc.edu.gh

M. E. Carr

The University of Melbourne, Melbourne, VIC, Australia

E. Ampadu

University of Ghana, Accra, Ghana

(C) The Author(s) 2019

P. Clarkson et al. (eds.), Values and Valuing in Mathematics Education,

ICME-13 Monographs, https://doi.org/10.1007/978-3-030-16892-6_6
} 
an opportunity to explore what students from poor countries that persistently perform poorly in international comparative educational assessment in mathematics and science (TIMSS) such as Ghana value in their learning of mathematics at school.

Ghana has participated in the last four TIMSS exercises, that is, in 2003, 2007, 2011, and 2015. The TIMSS (2011) reports have revealed that eighth grade students from Ghana performed at the lowest level when compared to grade matched students from the other participating countries (Mullis et al. 2012). Little research has been conducted in under-performing countries in international mathematics assessments such as TIMSS. Although most efforts to date have focused on high-performing countries, conducting research across the spectrum of performance is of equal importance. It is particularly important to note that values in mathematics education are believed to be related to the socio-cultural context of mathematics education (Bishop 2008). With this in mind, and in the spirit of inclusiveness, Ghana was invited to take part in the international 'What I Find Important (in my mathematics learning)' [WIFI] in 2015.

A survey of the 1,256 Ghanaian primary, junior high school (JHS) and senior high school (SHS) students who participated in the WIFI study revealed that they valued achievement, relevance, fluency, authority, ICT, versatility, learning environment, strategies, feedback, communication, fun, connections, engagement, applications, accuracy (Seah et al. 2017b). However, the data were not designed to be analysed to compare the valuing among students in the higher grade levels.

Valuing across grade levels is positioned as being important in this chapter because it sheds light on how valuing amongst students operating at various cognitive development levels compare. It also provides an avenue to relate the socio-cultural context of school at these levels to the valuing in mathematics education. In this chapter, our aim, therefore, is to contribute to the literature and practice on the effect of grade level on valuing in mathematics, by further exploring the Ghanaian data to understand whether grade level has an effect on what students find important in their mathematics learning. Exploring the effect of grade level is important to us because the stress or delight as students engage with more complex maths as they progress from one level to another in the school system is likely to bring out different values. In turn, these differences in students' enjoyment of mathematics may have some bearing on teaching techniques that are required to achieve optimal outcomes for all students.

We set the context for our study by providing a brief overview of the location of Ghana and mathematics education at the pre-tertiary level, a brief review of literature in the area of values/valuing in mathematics and mathematics education, and valuing across grade levels. Research methods and data collection procedures are described. Results on valuing across grade levels, discussion and conclusions are presented along with statements of implications for research and policy and practice. 


\subsection{School Mathematics in Ghana}

Ghana is located on the west coast of Africa. It was a British colony named Gold Coast. The country covers an area of $238,534 \mathrm{~km}^{2}$, with an estimated population in 2016 of 28.21 million (World Bank 2017). English language is the only national and official language of Ghana, although more than 50 indigenous languages are being spoken across the country. As with many sub-Saharan African countries, Ghana is a poor country with GNI per-capita of US\$1380 (2016 estimate) (World Bank 2017).

Ghana presently practices a 14-year pre-tertiary system of education, comprising two years of pre-school, six years of primary and six years of secondary school education. Children are expected to start pre-school at age four, and primary school at age six. During the first half of secondary school JHS students studying grades 7, 8, and 9 are typically aged between 12 and 15 years. During the second half of secondary school SHS students studying grades 10,11 , and 12 are typically aged between 16 and 19 years. This pre-tertiary level education is presently free and compulsory, and as such the rate of student enrolment is very high. Differentiation between tracks such as general science, arts and technical starts at the SHS level.

The study of mathematics is compulsory in all years of the pre-tertiary level, and the mathematical contents covered in the school curriculum at this level is comparable to those covered in countries all over the world. All mathematics textbooks are written in English, although from pre-school to primary three, pupils are expected to learn mathematics in the local language. From primary four onwards, they are expected to learn mathematics in English.

All SHS students study core mathematics while those who are studying sciencerelated courses take an additional mathematics course (elective mathematics). The use of information and communication technology in mathematics curriculum delivery in Ghana is limited (Mereku and Mereku 2014). Although the primary and JHS school mathematics syllabus recommend the use of calculators as a learning tool, students have very limited exposure to them. At these levels, calculators are prohibited in examinations. However, SHS school students have unlimited use of calculators, including in examinations and class exercises.

Students take internal examinations at the end of every term (approximately every 14-15 weeks), and external/national examinations organised by the West African Examination Council (WAEC) at the end of grades 9 (JHS three) and 12 (SHS three) respectively. WAEC is the regional examination body responsible for the assessment of the attained curriculum in the English speaking West African countries. Examinations at grade nine are meant for selection of students to the various programmes at the SHS school level. Examination at grade twelve is for selection of students to the various programmes at the university level. Stakes are usually very high in these examinations, and this often results in a situation where teachers have to teach to the test rather than employing approaches that enable students to acquire a conceptual understanding of concepts in attempts to finish the mathematics curriculum. The system is therefore often criticised as being examination dominated. 
Primary mathematics teachers are generalist educated, in the sense that they teach all the subjects (including music and physical education) at the primary school level. However, JHS and SHS mathematics teachers are specialised. The minimum qualification for teaching at the primary and JHS level is currently Diploma in Basic Education, while the minimum qualification for teaching mathematics at the SHS level is either B. Ed (Mathematics) or BSc (Mathematics) with post graduate certificate in education. However, it is common to find teachers with qualifications other than these two teaching at the SHS level due to shortage of qualified teachers in some districts.

\subsection{Values in Mathematics Education}

\subsubsection{Mathematical and Mathematics Educational Values}

In this section, we will focus mainly on what Bishop (1996) called mathematical and mathematics educational values because of the key roles which the two categories of these values play in the quality of students' learning experience (Seah et al. 2017a) and for that matter in the quality of their learning outcomes. Although we are aware of other general educational values, that relate to norms of the educational institutions, such as honesty and punctuality (see for example Bishop 1988, 2008), these will not form part of the key discussion in this section. While brief highlights of these values may be described herein to illuminate the current research problem, greater detail may be found in past and present literature on these values (Bishop 1988, 2008; Dede 2006, 2015; Seah et al. 2017a).

Values appear to mean different things in different contexts (Dede 2006) to different people. They could represent a variable in an equation in one context such as in the study of school mathematics. Or it could mean the worth of something if used in an everyday conversation involving commerce. In this chapter, we are looking at values from Mathews' (2001) perspective, that is, as mediators of learning behaviours. This perspective helps us to position what students find important in their study of mathematics as something that mediates their learning behaviour in mathematics.

Values have been described as the main dependent variable in the study of culture, society, and personality and the main independent variable in the study of social attitudes and behaviour (Rokeach 1973). While values have been widely researched in many disciplines, as recently as 2003 the exploration of the role of values in mathematics education was described as sadly neglected (Bishop et al. 2003). Meanwhile, literature suggests that it constitutes an important variable in mathematics curriculum delivery in schools (Bishop 2008).

Values in mathematics education have been defined as attributes of importance and worth that are internalised by an individual that provides him or her with the will and determination to maintain any course of action chosen in the learning and teaching of mathematics (Seah and Andersson 2015). Values in mathematics education are 
believed to regulate the way in which a student's or teacher's cognitive skills and emotional dispositions are aligned to learning or teaching aspects of mathematics (Seah et al. 2017a; Seah and Andersson 2015).

Different researchers have categorized values in mathematics and mathematics education differently (see Bishop 1988, 2008; Dede 2011, for examples). Bishop (1988) conceptualised the categories of mathematical values and mathematics educational values and argued that mathematical values are the values espoused by Western Mathematics. Bishop (2008) posits they are "values which have been developed as the knowledge of mathematics has developed within 'Westernised' cultures" (p. 83). These values convey to students the subtle message of what is important in the process of mathematizing (Seah et al. 2017a). Hence, mathematics educational values are embedded in mathematics curriculum, textbooks and mathematics classroom practices (Bishop 2008). These values also convey the subtle message to students of "what it takes to learn mathematics well" (Seah et al. 2017a, p. 336).

Bishop (1988) categorizes three pairs of complementary mathematical values relating to ideological, sentimental and sociological values as rationalismobjectivism, control-progress and mystery-openness respectively. Rationalism relates to mathematical argument, reasoning, logical analysis and explanation. On the other hand, objectivism relates to objectifying, concretising, symbolising and applying mathematical ideas. Valuing Control relates to mastery of rules, facts, procedure and established criteria, while Progress relates to valuing of alternative methods, development of new ideas and questioning of existing ones. For the last complementary pair, the valuing of Openness relates to valuing of proofs and individual explanations, while the valuing of Mystery relates to valuing of the wonder, fascination and the mystique of mathematical ideas (Bishop 2008, p. 84). Thus, as Bishop (1988) argues, that these pairs of values are complementary suggests the need for mathematics education to promote the growth of both for effective mathematical training. These categorisations of values provide us with the theoretical perspective to investigate what students at the various grade levels find important about both mathematics and the process of learning it.

What students and teachers value in mathematics relate to the socio-cultural context of mathematics education (Bishop 2008). It may be possible to have students from two or more different contexts of schooling valuing different attributes in mathematics (Seah et al. 2017a). Therefore, investigating students valuing in mathematics across context has the potential to provide insights about how socio-cultural context of education at these levels might influence what they find important in "the practice of doing mathematics" and "what it takes to learn mathematics well" (Seah et al. 2017a, p. 336). In turn, this has the potential to unearth possible dominant pedagogical practices in the school system.

In this section we have provided a brief review of the literature on valuing in mathematics and mathematics education, highlighting the various categorisations of values in mathematics and mathematics education. We have also highlighted the socio-cultural nature of values in mathematics education and positioned research studies on effect of valuing across grade levels are being necessary. In the next 
section we would look at what is known in the literature about values across grade levels.

\subsubsection{Values in Mathematics Education Across Grade Levels}

There is a dearth of research on what students value in mathematics across grade levels. Some studies have looked at what primary and secondary school teachers value in mathematics/mathematics education and reported differences in values for primary and secondary school teachers (Bishop et al. 2005; FitzSimons et al. 2001; Dede 2015). For example, in a comparative study involving sixty primary and secondary teachers from Germany and Turkey, Dede (2015) found that school levels of the teacher within and between Germany and Turkey had a significant effect on their mathematics educational values. Since there are differences between teachers, it may well be that the same will apply to students.

Other values research studies in the area of psychology have also looked at what students value generally across grade levels. In one study of individual values focusing on learning the routine and academic procrastination of sixth and eighth grade students in Germany, Dietz et al. (2007) found amongst other results that "6-graders appreciate achievement values more than 8-graders" (p. 10).

Studies on values across grade levels help to ascertain the effect of context of mathematics education across these levels on valuing in mathematics education since Mathematics curriculum delivery across these levels in many countries are not the same. For example, who qualifies to teach mathematics, what the mathematical training background of teachers is, and whether students choose to do more difficult mathematics, could be very different across schools. We therefore posit that school context has the tendency to affect what students value in their mathematics learning.

\subsection{The Research Context}

The WIFI study is an international research project involving 20 countries including Ghana, across five continents namely Africa, Asia, America, Australia and Europe (Seah et al. 2017b) at the time of this study. The project employs a quantitative approach involving questionnaire survey to investigate what students find important in their mathematics learning. Data collection has been conducted by local teams of researchers from the participating countries. Detailed current literature on the WIFI project and the justification of its methodologies is well documented in several studies (e.g. Seah et al. 2017a). In this chapter we will focus our discussion on how the WIFI methodology was adopted in the investigation of valuing by Ghanaian students at various grade levels. The research questions "What do primary, JHS, and 
SHS students' value in their mathematics learning?" and "How similar or different are mathematics students' values at primary, JHS, and SHS levels?"

\subsubsection{Research Instruments}

The validated questionnaire used for the WIFI Study was used to collect data in this study. The questionnaire is made up of four sections. The Likert-type scoring format was used for the first 64 items in Section A, in which students were asked to indicate how important mathematics pedagogical activities such as small-group discussions (item 3), connecting mathematics to real-life (item 12) and mathematics homework (item 57) were to them. A five-point scoring system was used, ranging from absolutely important (1 point) to absolutely unimportant (5 points). Section B consisted of continua dimensions, each related to two bipolar statements and respondents were asked to indicate along the continuum the extent to which their valuing leans towards one of the two statements. Section C consisted of four scenario-stimulated items, and Section D elicited the biographic data of the students. The English version was administered to Ghanaian students because English is the medium of instruction from grade four onward in Ghana. The questionnaire can be accessed at: https://melbourneuni. au1.qualtrics.com/jfe/form/SV_6YDuI41EnRFvozz.

\subsubsection{Participants}

The research participants in this representative sample were drawn from Governmentfunded public schools at the primary, JHS and SHS levels in the Cape Coast Metropolis of Ghana. A stratified random sampling procedure was used to select students from a mix of schools by achievement levels (Above Average, Average, Below Average) and by school context (i.e. rural and urban). The final set of 1,256 student participants consisted of 414 primary four, five and six, 426 JHS and 416 SHS students. The research participants attended 18 of the total possible 76 Government-funded public schools, whose enrolment totalled 42,257 students at the time this research was conducted.

\subsubsection{Data Analysis}

To answer the research questions: "What do primary, JHS, and SHS students' value in their mathematics learning?" and "How similar or different are mathematics students' values at primary, JHS, and SHS levels?"; a one-way Multivariate Analysis of Variance (MANOVA) was carried out. The MANOVA analysis afforded the opportunity to investigate the effect of grade level on valuing in mathematics, within acceptable 
error margin. A principal component analysis (PCA) with a varimax rotation and Kaiser normalization had been used to examine the questionnaire items, with significance level set at 0.05 , while a cut-off criterion for component loadings of 0.45 was used in interpreting the solutions. Items that did not meet the criteria were eliminated. According to the cut-off criterion, 23 items were removed and 41 items were retained from the original 64 . The analysis yielded 15 components with eigenvalues greater than one, which accounted for $52.73 \%$ of the total variance. Fifteen components of the students' set of values for mathematics learning were identified (Seah et al. 2017b). However, in MANOVA analysis, all components that had fewer than two item loadings were treated as weak factors and therefore excluded. This reduced the number of components from fifteen to seven: namely C1-Achievement (knowing the steps to solution, doing a lot of mathematics work etc.); C2-Relevance (stories about mathematics, explaining where rules/formulae came from etc.); C3-Fluency (practicing how to use maths formulae, explaining my solution to class); C4-Authority (explaining by the teacher, learning maths with computer); C5-ICT (using calculator to calculate, using calculator to check the answer); C6-Versatility (being lucky at getting the correct answer, looking for different possible answers); C7-Strategies (given a formula to use, shortcuts to solving mathematics problems). Grade levels formed the independent variable while the seven factors formed the dependent variable. Prior to the analysis, the data were screened to test for multivariate normality, homogeneity of covariance matrices (using Box's M test) and independence of observations. The details of the results obtained from the data analysis and the ensuing discussions, conclusions and implications are presented in the sections that follow.

\subsection{Results}

In this section, the MANOVA results of the 414 primary, 426 JHS and 416 SHS students who participated in the WIFI Ghana study are provided. The existence of statistically significant differences between primary, JHS and SHS students for each of the seven components (C1-Achievement, C2-Relevence, C3-Fluency, C4-Authority, C5-ICT, C6-Versatility, C7-Strategies) derived from the PCA, were investigated.

Pillai's Trace criterion was used to test whether there are significant group differences on a linear combination of the dependent variables. Since the multivariate effect for grade level is significant [Pillai's Trace value $=0.417, \mathrm{~F}(14,2496)=$ $46.932, \mathrm{p}<0.001$, partial eta square $=0.208$, the power to detect the effect $=1.000$ ], we interpreted the univariate between-subjects effects by adjusting for family-wise or experiment-wise error using a Bonferroni-type adjustment, and we derived the adjusted alpha level 0.007 (i.e. 0.05/7) (Coakes and Ong 2011). Using this alpha level, we have significant univariate main effects for each of the seven components:

- Component 1 (C1): achievement $[\mathrm{F}(2,1253)=137.74, \mathrm{p}<0.001$, partial eta square $\left(\eta^{2}\right)=0.180$, observed power $\left.=1.000\right]$ 
- Component 2 (C2): relevance $[\mathrm{F}(2,1253)=33.187, \mathrm{p}<0.001$, partial eta square $\left(\eta^{2}\right)=0.050$, observed power $\left.=1.000\right]$

- Component 3 (C3): fluency $[\mathrm{F}(2,1253)=27.608, \mathrm{p}<0.001$, partial eta square $\left(\eta^{2}\right)=0.042$, observed power $\left.=1.000\right]$

- Component 4 (C4): authority $[\mathrm{F}(2,1253)=10.266, \mathrm{p}<0.001$, partial eta square $\left(\eta^{2}\right)=0.016$, observed power $\left.=0.934\right]$

- Component 5 (C5): ICT $\left[\mathrm{F}(2,1253)=45.368, \mathrm{p}<0.001\right.$, partial eta square $\left(\eta^{2}\right)$ $=0.068$, observed power $=1.000]$

- Component $6($ C6): versatility $[\mathrm{F}(2,1253)=7.809, \mathrm{p}<0.001$, partial eta square $\left(\eta^{2}\right)=0.012$, observed power $\left.=0.826\right]$

- Component $7(C 7)$ : strategies $[\mathrm{F}(2,1253)=46.437, \mathrm{p}<0.001$, partial eta square $\left(\eta^{2}\right)=0.069$, observed power $\left.=1.000\right]$.

Tukey's Honestly Significant Difference (HSD) Post Hoc multiple comparisons test was conducted to further determine which differences are the sources of the significant $F$-ratio obtained for the overall MANOVA, that is, between which of the three groups (primary, JHS and SHS students) and the seven dependent variables (C1, C2, C3, C4, C5, C6 and C8) are significant differences found. Tukey's HSD Post Hoc test uses the harmonic mean sample size for unequal group sizes. Significant grade level pairwise differences were obtained in what students valued between primary students and both JHS and SHS students. The analysis showed that there are statistically significant differences between primary and JHS students for six out of the seven components $(\mathrm{C} 1, \mathrm{C} 2, \mathrm{C} 3, \mathrm{C} 4, \mathrm{C} 6$ and $\mathrm{C} 7)$ and primary and SHS students for four out of the seven components (C1, C2, C5 and C7). Statistically significant differences were also found between JHS and SHS students for four out of the seven components (C2, C3, C5 and C6). The estimated means for statistically significant components are indicated below:

- The primary students had the highest mean, followed by JHS students and SHS students (lowest) in Components 1,5 and 7. In other words, the SHS students valued $\mathrm{C} 1, \mathrm{C} 5$ and $\mathrm{C} 7$ more than their peers at other school levels;

- The primary students had the highest mean, followed by SHS students and the JHS students (lowest mean) in Components 3, 4 and 6;

- The SHS students had the highest mean, followed by the primary and JHS students (lowest mean) in Component 2.

In summary, a one-way MANOVA revealed a significant multivariate main effect for grade level [Pillai's Trace value $=0.417, \mathrm{~F}(14,2496)=46.932, \mathrm{p}<0.001$, partial eta square $=0.208$, the power to detect the effect $=1.000]$. Given the significance of the overall test, univariate main effects were examined. Significant univariate main effects were obtained for each of the seven dependent variables. Table 6.1 presents the summary of grade level pairwise differences among the various grade levels and their significance level.

Table 6.1 shows that there were significant grade level pairwise differences in C1, C2, C3, C4, C6 and C7 between primary and JHS students, C1, C2, C5 and C7 between primary and SHS students and C2, C3, C5 and C6 between SHS and JHS students. 
Table 6.1 Grade level pairwise differences

\begin{tabular}{l|l|l|c|l|r|l}
\hline $\begin{array}{l}\text { Dependent } \\
\text { variable }\end{array}$ & $\begin{array}{l}\text { Mean diff } \\
\text { Pri/JHS }\end{array}$ & P-value & $\begin{array}{l}\text { Mean diff } \\
\text { Pri/SHS }\end{array}$ & P-value & $\begin{array}{l}\text { Mean diff } \\
\text { JHS/SHS }\end{array}$ & P-value \\
\hline Achievement-C1 & 0.5115 & 0.000 & 0.5898 & 0.000 & 0.0783 & 0.103 \\
\hline Relevance-C2 & 0.1982 & 0.000 & -0.2036 & 0.000 & -0.4017 & 0.000 \\
\hline Fluency-C3 & 0.5264 & 0.000 & 0.1211 & 0.238 & -0.4053 & 0.000 \\
\hline Authority-C4 & 0.2639 & 0.000 & 0.1763 & 0.009 & -0.0876 & 0.301 \\
\hline ICT-C5 & 0.0598 & 0.638 & 0.5755 & 0.000 & 0.5157 & 0.000 \\
\hline Versatility-C6 & 0.2090 & 0.001 & 0.0166 & 0.958 & -0.1924 & 0.003 \\
\hline Strategy-C7 & 0.4503 & 0.000 & 0.5077 & 0.000 & 0.0575 & 0.576 \\
\hline
\end{tabular}

\subsection{Discussion}

This study investigated the effect of grade level on what Ghanaian students find important in their study of mathematics. The results suggest that there were statistically significant differences between primary, JHS and SHS students for seven components namely, achievement, relevance, fluency, authority, ICT, versatility, and strategies.

The results showed a decrease in the estimated marginal mean scores for grade level from primary, JHS and SHS students respectively for the valuing of achievement (doing a lot of mathematics work, knowing the steps to solution, knowing which formula to use, understanding why a solution is incorrect or correct), ICT (using calculator to check the answer, using calculator to calculate) and strategies (short cuts to solving mathematics problem, given a formula to use). These attributes relate to the mastery of mathematics content hence one can argue that primary school students value having mastery of mathematics content less than JHS and SHS students, while JHS students also value mastery of mathematics content lesser as compared to SHS students.

Valuing "given formula to use" and "shortcuts to solving mathematics problem" (Strategies) and "knowing the steps of solutions", "knowing which formula to use" and "understanding why my solution is incorrect or correct" (Achievement), relates more to what Bishop (2008) describes as "... power of mathematical knowledge through mastery of rules, facts, procedures and established criteria” (p. 85), which relates to sentimental value of control in values in western mathematics. Our results, therefore, suggest that valuing of control increases as one moves up grade levels.

The finding regarding the valuing of the use of ICT in mathematics (that is, using calculators to check the answer and using a calculator to calculate) is not surprising. Having been exposed to the use of calculators and other ICT tools more than primary and JHS students, one would expect the SHS students to appreciate the affordances they offer in the teaching and learning of mathematics than the primary and the JHS students. All (primary, JHS and SHS) students find mathematics difficult and see the calculator as a tool with which they can carry out calculations without necessarily 
recalling number facts or algorism. However, the primary and the JHS students have very limited exposure to the calculator and other ICT tools in their lessons, even though the mathematics syllabus recommends them to do so. At the SHS level, it is possible that the students have gone over this restrictive pre-SHS level belief about the use of ICT tools such as calculators just for checking results after one had applied an algorithm. They would likely have realised the other benefits of calculators and ICT tools in supporting their mathematics learning, such as promoting in-depth understanding of concepts. This is because at the SHS level students are exposed to the use of calculator and other ICT tools. Many of the SHS students might have now realised that the calculator and the other ICT tools play a major role in their success in mathematics learning so far. They might have begun to place more importance on the use of ICT. We argue that the socio-cultural context of mathematics education in Ghana has shaped the valuing of ICT among the SHS students and the primary and JHS students. The restrictive use of ICT by pre-SHS students in their mathematics learning as compared to the SHS students might have shaped what they value in their mathematics.

There was also a decrease in the estimated marginal means - and thus, an increase in valuing-from primary to JHS/SHS levels in the student valuing of fluency (explaining my solution to class, practicing how to use maths formula), authority (learning maths with internet and explaining by the teacher) and versatility (looking for different possible answers, being lucky at getting the correct answer). Both the JHS and SHS students valuing of attributes such as practising how to use mathematics formula, explaining by the teacher and being lucky to get correct answers more than Primary school students supports our earlier observation about increase in valuing of mastery/control over mathematics content as one moves up grade levels.

There was an upward trend with estimated marginal mean score increasing with grade level for the valuing of relevance. In fact, SHS students valued relevance in their mathematics learning less than both primary and JHS students. They valued attributes such as stories about mathematics, explaining where rules/formulae came from, the mystery of mathematics, stories about recent developments in mathematics, using concrete materials to understand mathematics less than both the primary and JHS students. These attributes generally relate to the sociological values of openness and mystery in values in western mathematics (Bishop 1988). Explaining where rules/formulae came from and using concrete materials to understand mathematics relates to openness. While stories about mathematics, stories about recent developments in mathematics and mystery of mathematics relate to the mystery (Bishop 2008, p.85).

This shows that SHS students value sociological values of openness and mystery less than both primary and JHS students. The SHS students are more interested in mastery than understanding mathematics. This may be because at the SHS level the breadth and depth of mathematics contents that have to be covered are high and the pressure of high-stake national examinations may be a contributory factor. 


\subsection{Conclusions and Implications}

This study has contributed to our understanding of how students' valuing develops across grade levels in Ghana. We investigated whether grade level had an effect on what primary, JHS and SHS students value in mathematics. A one-way MANOVA revealed a significant multivariate main effect for grade level [Pillai's Trace value $=0.417, \mathrm{~F}(14,2496)=46.932, \mathrm{p}<0.001$, partial eta square $=0.208$, the power to detect the effect $=1.000$ ]. Given the significance of the overall test, univariate main effects were examined, and this also revealed significant univariate main effects for each of the seven dependent variables namely achievement, relevance, fluency, authority, ICT, versatility and strategies.

We, therefore, conclude that interesting differences in valuing in mathematics education across grade levels do exist for primary, JHS and SHS students. The mathematical value of control (Bishop 1988) seems to be embraced more by students in higher grade levels from JHS to SHS. The SHS school students valued achievement, ICT and strategies more than JHS and Primary school students, while the JHS students also valued these attributes more than their peers in Primary schools. Thus, we might suggest that values evolve within each person at least throughout the schooling years, if not over an even longer period of time.

The findings from this study appear to suggest that all the seven values are embraced by the students, except that some of them are more highly prioritised at different stages of schooling. For example, while control is valued at all levels, it is prioritised at the SHS level as compared to the Primary and JHS levels.

The findings from this study have implications for further research. In order to provide a better understanding of valuing across grade level, it might be important to ascertain through research, not only on how students' values reflect those of their teachers but also how values espoused by curriculum materials such as the syllabus and textbooks reflect those of the students. Future studies, such as the WhyFI study being led by a Hong Kong team, are using methodologies that investigate the reasons behind observed trends emerging from large scale surveys such as the one reported here. Although the sample for the study was large enough to support generalisation of our findings, it is important to state that the study was conducted in only one out of ten regions in Ghana. The findings might therefore not reflect the entire situation in Ghana. Hence future studies might also include samples from the other regions in the country.

\section{References}

Bishop, A. J. (1988). Mathematical enculturation a cultural perspective on mathematics education. Dordrecht, The Netherlands: Kluwer.

Bishop, A. J. (1996, June 3-7). How should mathematics teaching in modern societies relate to cultural values-some preliminary questions? In Paper presented at the Seventh Southeast Asian Conference on Mathematics Education, Hanoi, Vietnam. 
Bishop, A. J. (2008). Teachers' mathematical values for developing mathematical thinking in classrooms: Theory, research and policy. The Mathematics Educator, 11(1/2), 79-88.

Bishop, A. J., Clarke, B., Corrigan, D., \& Gunstone, D. (2005). Teachers' preferences and practices regarding values in teaching mathematics and science. In P. Clarkson, A. Downton, D. Gronn, M. Horne, A. McDonough, R. Pierce, \& A. Roche (Eds.). Building connections: Theory, research and practice, proceedings of the 28th annual conference of Mathematics Education Research Group of Australasia, (pp. 153-160). Melbourne, MERGA.

Bishop, A. J., Seah, W. T., \& Chin, C. (2003). Values in mathematics teaching-the hidden persuaders? In A. Bishop, M. A. Clements, C. Kietel, J. Kilpatrick, \& F. Leung (Eds.), Second international handbook of mathematics education (pp. 717-765). Dordrecth: Kluwer Accademic Publishers.

Chin, C., \& Lin, F. L. (2000). A case study of a mathematics teacher's pedagogical values: Use of a methodological framework of interpretation and reflection. http://140.122.140.1/ cchin/file01. pdf.

Coakes, S. J., \& Ong, C. (2011). SPSS verion18 for windows: Analysis without anguish. Milton, Qld, Australia: Wiley.

Dede, Y. (2006). Values in Turkish middle school mathematics textbooks. Quality \& Quantity, 40, 331-359.

Dede, Y. (2011). Mathematics education values questionnaire for Turkish preservice mathematics teachers: Design, validation and results. International Journal of Science and Mathematics Education, 9(3), 603-626.

Dede, Y. (2015). Comparing primary and secondary mathematics teachers' perferences regarding values about mathematics teaching in Turkey and Germany. International Journal of Science and Mathematics Education, 13, 227-255.

Dietz, F., Hofer, M., \& Fries, S. (2007). Individual values, learning routines, and academic procastination. British Journal of Educational Psychology, 77, 893-906.

FitzSimons, G., Seah, W. T., Bishop, A. J., \& Clarkson, P. (2001). Beyond numeracy: Values in mathematics classroom. In J. Bobis, B. Berry, \& M. Mitchelmore (Eds.). Numeracy and beyond. Proceedings of the 23rd Annual Conference of Mathematics Education Research Group of Australasia, (pp. 202-209). Fremantle: MERGA.

Mathews, B. (2001). The relationship between values and learning. International Education Journal, 2(4), 223-232.

Mereku, D. K., \& Mereku, C. W. K. (2014). Congruence between the intended, implemented and attained ICT curricula in sub-Saharan Africa. Online: www.tandfonline.com/dpi/abs/10.1080/ 14926156.2014.992555.

Mullis, I. V. S., Martin, M. O., Foy, P., \& Arora, A. (2012). TIMSS 2011 International Results in Mathematics. Chestnut Hill, MA. https://timssandpirls.bc.edu.

Rokeach, M. (1973). The Nature of human values. New York: Free Press.

Seah, W. T., \& Andersson, A. (2015). Valuing diversity in mathematics pedagogy through the volitional nature and alignment of values. In A. Bishop, H. Tan, \& T. Barkatsas (Eds.), Diversity in mathematics education: Towards inclusive practices (pp. 167-183). Switzerland: Springer.

Seah, W. T., Baba, B., \& Zhang, Q. (2017a). The WIFI study students valuing in Hong Kong and Japan. In J. W. Son, T. Watanabe, \& J. Lo. (Eds). What matters? Research Trends in International Comparative Studies in Mathematics Education, Research in Mathematics Education (pp. 333-354). New York, Springer.

Seah, W. T., Davis, E. K., \& Carr, M. E. (2017b). School mathematics education through the eyes of students in Ghana: Extrinsic and intrinsic valuing. In 10th Congress of European Research in Mathematics Education. https://minerva-access.unimelb.edu.au.

Seah, W. T., \& Wong, N. Y. (2012). What students value in effective mathematics learning: a 'Third Wave Project' research study. ZDM: The International Journal on Mathematics Education, 44, 33-43.

World Bank. (2017). Ghana data. https://data.worldbank.org. 
Open Access This chapter is licensed under the terms of the Creative Commons Attribution 4.0 International License (http://creativecommons.org/licenses/by/4.0/), which permits use, sharing, adaptation, distribution and reproduction in any medium or format, as long as you give appropriate credit to the original author(s) and the source, provide a link to the Creative Commons license and indicate if changes were made.

The images or other third party material in this chapter are included in the chapter's Creative Commons license, unless indicated otherwise in a credit line to the material. If material is not included in the chapter's Creative Commons license and your intended use is not permitted by statutory regulation or exceeds the permitted use, you will need to obtain permission directly from the copyright holder.

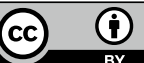

